\title{
Development of crosslinkable poly(lactic acid-co-glycidyl methacrylate) copolymers and their curing behaviors
}

\begin{abstract}
Atitsa Petchsuk ${ }^{1}$, Wilairat Submark ${ }^{1}$ and Pakorn Opaprakasit ${ }^{2}$
Crosslinkable poly(lactic acid-co-glycidyl methacrylate), P(LLA-co-GMA), copolymer was systematically synthesized by ringopening polymerization. Synthesis parameters, i.e., catalyst type, comonomer ratio and polymerization time and temperature were studied. The incorporated GMA content strongly affected the physical and thermal properties of the obtained copolymers, which varied from semi-crystalline to completely amorphous polymers. Melting and glass transition temperatures, and molecular weights of the copolymers decreased as the GMA content in the copolymer increased. Curing behavior of the copolymers was assessed by employing thermo- and photo-crosslinking processes, and the crosslink density was evaluated via their gel content and solvent swelling ratio. A photo-crosslinking process was proven as a practical method in the curing of the copolymers, as the reaction was almost complete within $2 \mathrm{~min}$, as indicated by a gel content of $96 \%$. In the thermo-crosslinking process, at least a 15 -min curing time was required at $120^{\circ} \mathrm{C}$. The cured products of copolymers with $19.2 \mathrm{~mol} \%$ GMA showed the highest compressive stress at $25.5 \mathrm{MPa}$.
\end{abstract}

Polymer Journal (2013) 45, 406-412; doi:10.1038/pj.2012.159; published online 29 August 2012

Keywords: compressive stress; crosslink; glycidyl methacrylate; polylactic acid; polymer synthesis

\section{INTRODUCTION}

Biodegradable polymers have received increasing attention, and are widely used in various applications, especially in biomedical, packaging, agriculture and environmental fields. Polylactic acid (PLA) is among the most popular biodegradable polymers, as this not only possesses good mechanical properties, but is also biocompatible and biodegradable. Nonetheless, low thermal stability, brittleness, low gasbarrier and lack of functionality are its shortcomings. To overcome these drawbacks, many approaches have been performed, such as stereo-complexation, copolymerization, molecular design and blending with other polymers. ${ }^{1-14}$

Copolymerization of lactide with specific functional comonomers is of interest for introducing functionality into PLA chains. Louis et al. ${ }^{14}$ reported the synthesis of a copolymer of lactide and glycidol by ring-opening polymerization. The resulting hyper-branched poly(lactic acid-co-glycidol) copolymer contained hydroxyl groups, which served as reactive sites for further modifications, such as a curing reaction to generate thermoset copolyester. However, content and placement of these hydroxyl functional groups were not well defined, as these are also correlated with other factors, that is, $T_{g}$, molecular weight, mechanical properties, structures and architectures of the copolymer. It is a challenge to control molecular weight, structures and chain topology of a copolymer.
In our attempt to overcome this challenge, we have developed a synthesis process of random poly(lactic acid-co-glycidol) copolymer, whose molecular weight and hydroxyl content are adjustable by varying the molar ratio of lactyl to glycidol units in feed. ${ }^{15}$ Incorporating of methacrylate groups is also of interest. Glycidyl methacrylate (GMA) has been employed as a reactive compatibilizer in polymer blends. ${ }^{16-18}$ Methacrylic anhydride has been used in preparation of crosslinked poly( $\varepsilon$-caprolactone) and polylactide oligomers. ${ }^{19-20}$ Nonetheless, these reactive functional groups have rarely been incorporated and distributed along PLA polymer chains.

In this work, a synthesis route of a new functionalized PLA copolymer, poly(lactic acid-co-glycidyl methacrylate), P(LLA-coGMA), is developed. Effects of polymerization conditions, that is, temperature, time, comonomers feed ratio and catalyst type on structures and properties of the copolymer are investigated. Curing behavior of the copolymer is evaluated by employing photo- and thermo-crosslinking processes. Mechanical properties of the resulting cured copolymer are also examined in terms of compressive stress.

\section{EXPERIMENTAL PROCEDURE}

Materials

L-lactide monomer was prepared in our laboratory, and purified by recrystallization in ethyl acetate. Tin octoate, $\mathrm{Sn}(\mathrm{Oct})_{2}$, was purchased from Wako

${ }^{1}$ Polymer Research Unit, National Metal and Materials Technology Center, Pathumthani, Thailand and ${ }^{2}$ School of Bio-Chemical Engineering and Technology, Sirindhorn International Institute of Technology (SIIT), Thammasat University, Pathumthani, Thailand

Correspondence: Dr A Petchsuk, Polymer Research Unit, National Metal and Materials Technology Center, Thailand Science Park, Pathumthani 12120, Thailand. E-mail: atitsp@mtec.or.th

Received 28 May 2012; revised 18 July 2012; accepted 19 July 2012; published online 29 August 2012 
(Tokyo, Japan). Ethyl acetate, chloroform, ethanol and toluene solvents were purchased from Lab Scan (Bangkok, Thailand). GMA, magnesium ethoxide, $\mathrm{Mg}(\mathrm{OEt})_{2}$, and benzoyl peroxide thermo-initiator were purchased from SigmaAldrich (St Louis, MO, USA). Camphorquinone photo-initiator was purchased from ESSTECH (Essington, PA, USA), and 2-dimethylaminoethyl methacrylate was purchased from Fluka (St Louis, MO, USA). All chemicals were used as received.

\section{Synthesis of P(LLA-co-GMA)}

$\mathrm{P}$ (LLA-co-GMA) was synthesized by ring-opening polymerization using a 90/10 LLA/GMA molar feed ratio. Effect of catalyst types on reaction efficiency and properties of the copolymer was investigated by employing $\mathrm{Sn}(\mathrm{Oct})_{2}$, $\mathrm{Mg}(\mathrm{OEt})_{2}$ and $\left(\mathrm{C}_{6} \mathrm{H}_{5}\right)_{4} \mathrm{Sn}$. The reaction was conducted in a bulk process using $0.3 \mathrm{~mol} \%$ catalyst, with the polymerization temperature and time set at $100{ }^{\circ} \mathrm{C}$ and $24 \mathrm{~h}$, respectively. Effect of polymerization conditions on properties and structures of the copolymers was also examined by varying reaction temperatures and times at 80,90 and $100^{\circ} \mathrm{C}$ for 4,10 and $24 \mathrm{~h}$. For the study on effect of GMA feed contents, the reactions were carried out in tetrahydrofuran (THF) solution at $100^{\circ} \mathrm{C}$ for $24 \mathrm{~h}$, with the GMA content ranging from 2,5 , 10,20 and $30 \mathrm{~mol} \%$.

\section{Crosslinking process of P(LLA-co-GMA)}

Curing behaviors of P(LLA-co-GMA) copolymers containing various GMA contents were studied by photo- and thermo-crosslinking processes. Samples in a disk form with a diameter of $1.0 \mathrm{~cm}$ and thickness of $0.5 \mathrm{~cm}$ were prepared. In the photo-crosslinking process, the copolymer was first dissolved in chloroform. Camphorquinone photo-initiator (1 wt \% of copolymer) and 2-dimethylaminoethyl methacrylate reactive monomer (1:1 by wt on Camphorquinone basis) were then added. The solution was dry-cast to form disk specimens. The samples were then irradiated under visible blue light at a wavelength of $468 \mathrm{~nm}$ using 3M ESPE Elipar 2500 (3M ESPE Dental Supplies, St Paul, MN, USA) at various crosslinking times. In a thermo-crosslinking process, P(LLA-co-GMA) was first dissolved in chloroform. Benzoyl peroxide ( $2 \mathrm{wt} \%$ ) was then added to the solution. The mixture was stirred at room temperature and dry-cast as sample discs. The crosslinking process was then conducted in a vacuum oven by setting appropriate temperatures and times.

\section{Characterizations}

Average molecular weights and molecular weight distributions $\left(M_{n}, M_{w}\right.$ and PDI) were measured by gel permeation chromatography using a Waters $150-\mathrm{CV}$ gel permeation chromatograph and employing a mono-disperse polystyrene standard. The glass transition $\left(T_{\mathrm{g}}\right)$ and melting temperatures $\left(T_{\mathrm{m}}\right)$ of the copolymer were determined by differential scanning calorimeter (DSC) on a DSC822 ${ }^{\mathrm{e}}$ mettler Toledo. The sample was scanned twice from -20 to $200^{\circ} \mathrm{C}$ with a heating and cooling rate of $20.0^{\circ} \mathrm{C} \mathrm{min}^{-1}$. All data were taken from the second scan. Chemical structures of the copolymer were examined using an
AVENCE $300 \mathrm{MHz}$ digital nuclear magnetic resonance spectrometer (NMR, Bruker Biospin; DPX-300, Rheinstetten, Germany) and fourier transform infrared spectrometer (FTIR, EQUINOX55, Bruker, Optics, Ettlingen, Germany).

Compressive stress of the cured samples was measured on a universal testing machine (UTM, Instron model 55R4502, Instron Corp., Norwood, MA, USA) with a crosshead speed of $50 \mathrm{~mm} \mathrm{~min}^{-1}$. Sample disk specimens with $1.0 \mathrm{~cm}$ diameter and $0.5 \mathrm{~cm}$ thickness were prepared according to McCabe's method. ${ }^{21}$ Gel content of the cured products from both thermal- and photo-crosslinking processes was determined by extracting with THF for $24 \mathrm{~h}$ and vacuum drying the insoluble fraction at $50^{\circ} \mathrm{C}$ for overnight before weighing. The gel content was calculated from the weight ratio of the dried THF-insoluble fraction and the original sample. Degree of swelling was examined by immersing disk specimens in THF at room temperature. The specimen was removed at equilibrium swelling time, the time when its solvent uptake reached a constant value, wiped with filter paper and weighed. The degree of swelling was then calculated, as follows:

$$
\% \text { swelling }=\frac{W_{\mathrm{eq}}-W_{\mathrm{o}}}{W_{\mathrm{o}}} \times 100
$$

where $W_{\mathrm{o}}=$ original weight of dried sample $(\mathrm{g})$

$W_{\text {eq }}=$ weight of swollen sample at equilibrium swelling time $(\mathrm{g})$

\section{RESULTS AND DISCUSSION}

\section{Chemical structures and compositions}

Chemical structures and compositions of the P(LLA-co-GMA) copolymer were examined by ${ }^{1} \mathrm{H}$ NMR spectrum, as shown in Figure 1. Characteristic peaks of lactyl units were observed at 5.1$5.2\left(\mathrm{H}^{\mathrm{b}}\right)$ and 1.5-1.7 p.p.m. $\left(\mathrm{H}^{\mathrm{a}}\right)$, which corresponded to methine proton $\left(-\mathrm{O}=\mathrm{C}-\mathrm{CH}-\left(\mathrm{CH}_{3}\right)-\mathrm{O}\right)$ and methyl protons $(-\mathrm{O}=\mathrm{C}-\mathrm{CH}-$ $\left.\left(\mathrm{CH}_{3}\right)-\mathrm{O}\right)$, respectively. The signal located at 4.3-4.4 p.p.m. $\left(\mathrm{H}^{\mathrm{c}}\right)$ was assigned to methine proton at chain end $\left(-\mathrm{O}=\mathrm{C}-\mathrm{CH}-\left(\mathrm{CH}_{3}\right)-\mathrm{OH}\right)$ of lactyl unit. Peaks associated with GMA appeared at 6.1 and 5.2 p.p.m. $\left(\mathrm{H}^{\mathrm{h}}\right)$, assigned to protons next to methacrylic double-bond $\left(-\mathrm{O}=\mathrm{C}-\mathrm{C}\left(\mathrm{CH}_{3}\right)=\mathrm{CH}_{2}-\right)$. The signal at 3.7 p.p.m. $\left(\mathrm{H}^{\mathrm{e}}\right)$ was due to methylene protons of $\left(-\mathrm{O}-\mathrm{CH}_{2}-\mathrm{CH}-\mathrm{O}\right)$ in the backbone, whereas those located at $4.1-4.3$ p.p.m. $\left(\mathrm{H}^{\mathrm{d}}, \mathrm{H}^{\mathrm{f}}\right)$ were assigned to methine proton $\left(-\mathrm{O}-\mathrm{CH}-\mathrm{CH}_{2}-\mathrm{O}\right)$ and methylene protons $\left(-\mathrm{O}-\mathrm{CH}-\mathrm{CH}_{2}-\mathrm{O}\right)$ on side chains. The peak at 2.0 p.p.m. $\left(\mathrm{H}^{\mathrm{g}}\right)$ represented methyl protons located next to the double-bond of comonomer unit $\left(-\left(\mathrm{CH}_{3}\right) \mathrm{C}=\mathrm{CH}_{2}\right)$.

\section{Effect of catalyst types}

Various catalysts, that is, $\mathrm{Sn}(\mathrm{Oct})_{2}, \mathrm{Mg}(\mathrm{OEt})_{2}$ and $\left(\mathrm{C}_{6} \mathrm{H}_{5}\right)_{4} \mathrm{Sn}$, were used in the synthesis of P(LLA-co-GMA) using a 10-mol\% GMA feeding content in a bulk process. Chemical structures and properties

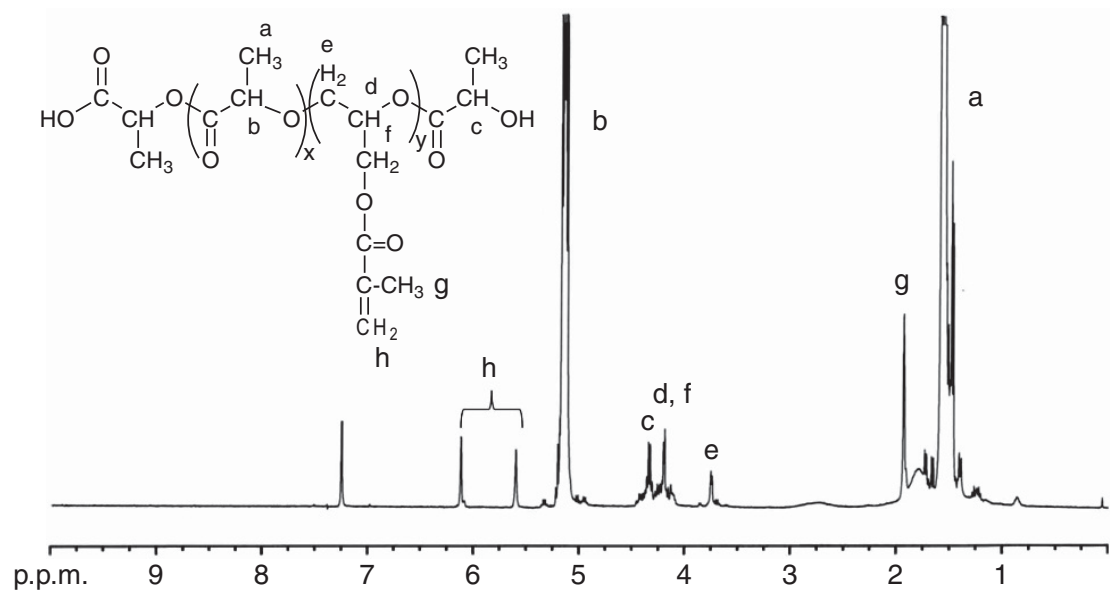

Figure $1{ }^{1} \mathrm{H}$ NMR spectrum of P(LLA-co-GMA) copolymer. 
of the resulting copolymers are presented in Table 1 . The incorporation of GMA in the copolymer chains was 7.2 and $6.5 \mathrm{~mol} \%$ when $\mathrm{Sn}(\mathrm{Oct})_{2}$ and $\mathrm{Mg}(\mathrm{OEt})_{2}$ were employed, respectively. However, a relatively-low GMA composition ( $3.4 \mathrm{~mol} \%)$ in the copolymer chains was obtained when $\left(\mathrm{C}_{6} \mathrm{H}_{5}\right)_{4} \mathrm{Sn}$ was used. This is likely owing to the sterically bulky $\left(\mathrm{C}_{6} \mathrm{H}_{5}\right)_{4} \mathrm{Sn}$ groups obstruct the insertion of incoming comonomers. This is also reflected by the molecular weight of the resulting copolymers, where those with higher $\mathrm{M}_{\mathrm{w}}$ were produced from $\mathrm{Sn}(\mathrm{Oct})_{2}\left(9131 \mathrm{~g} \mathrm{~mol}^{-1}\right)$ and $\mathrm{Mg}(\mathrm{OEt})_{2}\left(6566 \mathrm{~g} \mathrm{~mol}^{-1}\right)$ compared with that of $\left(\mathrm{C}_{6} \mathrm{H}_{5}\right)_{4} \mathrm{Sn}\left(5930 \mathrm{~g} \mathrm{~mol}^{-1}\right)$.

All copolymers showed lower $T_{\mathrm{m}}$ than that of PLA homopolymer $\left(178^{\circ} \mathrm{C}\right)$. Effect of catalyst types on $T_{\mathrm{m}}$ and $\Delta H_{\mathrm{m}}$ of the copolymers in descending order is as follows; $\mathrm{Sn}(\mathrm{Oct})_{2}>\mathrm{Mg}(\mathrm{OEt})_{2}>\left(\mathrm{C}_{6} \mathrm{H}_{5}\right)_{4} \mathrm{Sn} . T_{\mathrm{g}}$ of the copolymers were observed in the range of $21-36^{\circ} \mathrm{C}$, which were also lower than that of PLLA $\left(55.9^{\circ} \mathrm{C}\right)$ and PGMA $\left(84^{\circ} \mathrm{C}\right)$. A copolymer with the lowest $T_{\mathrm{g}}$ was obtained when $\mathrm{Mg}(\mathrm{OEt})_{2}$ catalyst was employed, probably because this material consists of large fractions of low MW chains with high MW distribution (1.6 times higher than other samples). The decrease of $T_{\mathrm{m}}$ and $\Delta H_{\mathrm{m}}$ of the copolymers is largely because the incorporated comonomer units act as defects that interrupt the long crystalline sequence of PLA. The low MW nature of the copolymers also has a major role in the reduction of $T_{\mathrm{m}}$ and crystallinity of the copolymers, where apparent correlation in these values is observed. Nonetheless, the results conclusively indicate that $\mathrm{Sn}(\mathrm{Oct})_{2}$ is the most appropriate catalyst for this reaction.

\section{Effects of polymerization temperature and time}

P(LLA-co-GMA) were synthesized using 20 and $30 \mathrm{~mol} \%$ GMA in feed, at different polymerization temperatures and times, that is, 80 ,
90 and $100{ }^{\circ} \mathrm{C}$ for 4,10 and $12 \mathrm{~h}$. Properties of the resulting copolymers are shown in Table 2 . With the use of $30 \mathrm{~mol} \%$ GMA feeding and a 12 -h reaction time, a low GMA content $(8.5 \mathrm{~mol} \%)$ was incorporated into the copolymer chain when the reaction was carried out at 80 or $90^{\circ} \mathrm{C}$. In contrast, a crosslinked copolymer network was directly obtained upon increasing the polymerization temperature to $100^{\circ} \mathrm{C}$. This is likely due to a long polymerization time. As a result, the reaction time was shortened to 10 and $4 \mathrm{~h}$. It was found that at $10 \mathrm{~h}$ polymerization time, the auto-crosslinking reaction still occurred, despite the reduction of the mol\% GMA feeding. However, a further decrease in polymerization time to $4 \mathrm{~h}$ generated a copolymer that was completely soluble in THF. Moreover, the molecular weight of the resulting copolymer was also higher than that synthesized at lower polymerization temperature.

\section{Effect of comonomer feed ratios}

Effect of comonomer composition on the properties of P(LLA-coGMA) was investigated by varying LLA:GMA molar feeding ratios at 98:2, 95:5, 90:10, 80:20 and 70:30. Figure 2 shows ${ }^{1} \mathrm{H}$ NMR spectra of the resulting $\mathrm{P}$ (LLA-co-GMA) copolymers as a function of comonomer feed ratios. Integration of GMA signals at 6.1 and 5.2 p.p.m., due to methylene protons next to the double-bond, clearly increased with GMA content in the copolymer chains. The copolymer compositions were calculated from the ratio of integration of peaks at 6.1 or 5.2 p.p.m. to that at 5.3 p.p.m. (methine proton of L-lactide monomer units). The results, as summarized in Table 3 , indicated that the GMA composition in the copolymer chains were lower than those in the feed, and the difference increased with the GMA feed contents. The molecular weights of the copolymers decreased with an increase of

Table 1 Effect of catalyst types on structures and properties of P(LLA-co-GMA) copolymers

\begin{tabular}{|c|c|c|c|c|c|c|c|c|}
\hline \multirow[b]{2}{*}{$\begin{array}{l}\text { LLA/GMA molar } \\
\text { feed ratio }\end{array}$} & \multirow[b]{2}{*}{ Catalyst } & \multirow[b]{2}{*}{$\begin{array}{c}\text { LLA/GMA composition } \\
\left({ }^{1} H \text { NMR }\right)\end{array}$} & \multicolumn{3}{|c|}{ Thermal properties } & \multicolumn{3}{|c|}{ Molecular weight } \\
\hline & & & $\begin{array}{l}\mathrm{T}_{g} \\
(\mathrm{C})\end{array}$ & $\begin{array}{l}\mathrm{T}_{m} \\
(\mathrm{C})\end{array}$ & $\begin{array}{c}\Delta \mathrm{H}_{m} \\
\left(\mathrm{~J} \mathrm{~mol}^{-1}\right)\end{array}$ & $\begin{array}{l}\mathrm{M}_{n} \times 10^{3} \\
\left(\mathrm{gmol}^{-1}\right)\end{array}$ & $\begin{array}{l}\mathrm{M}_{w} \times 10^{3} \\
\left(\mathrm{gmol}^{-1}\right)\end{array}$ & PDI \\
\hline $90 / 10$ & $\mathrm{Sn}(\mathrm{Oct})_{2}$ & $92.8 / 7.2$ & 36.7 & 147.9 & 50.2 & 7.21 & 9.13 & 1.3 \\
\hline $90 / 10$ & $\mathrm{Mg}(\mathrm{OEt})_{2}$ & $93.5 / 6.5$ & 21.5 & 122.7 & 15.9 & 3.17 & 6.57 & 2.1 \\
\hline $90 / 10$ & $\mathrm{Sn}\left(\mathrm{C}_{6} \mathrm{H}_{5}\right)_{4}$ & $96.6 / 3.4$ & 36.4 & 112.8 & 13.5 & 4.66 & 5.93 & 1.3 \\
\hline
\end{tabular}

Abbreviations: GMA, glycidyl methacrylate; LLA, lactic acid; NMR, nuclear magnetic resonance; P(LLA-co-GMA), poly(lactic acid-co-glycidyl methacrylate); PDI, polydispersity index.

Table 2 Effects of polymerization temperature and time on properties of P(LLA-co-GMA)

\begin{tabular}{|c|c|c|c|c|c|c|c|}
\hline \multirow[b]{2}{*}{$\begin{array}{l}\text { LLA/GMA molar } \\
\text { feed ratio }\end{array}$} & \multirow[b]{2}{*}{$\begin{array}{l}\text { Time } \\
\text { (h) }\end{array}$} & \multirow[b]{2}{*}{$\begin{array}{l}\text { Temp } \\
\left({ }^{\circ} \mathrm{C}\right)\end{array}$} & \multirow[b]{2}{*}{ Catalyst } & \multirow[b]{2}{*}{$\begin{array}{c}\text { LLA/GMA polymer } \\
\text { composition ( }{ }^{1} H \text { NMR) }\end{array}$} & \multicolumn{3}{|c|}{ Molecular weight } \\
\hline & & & & & $\begin{array}{l}\mathrm{M}_{n} \times 10^{3} \\
\left(\mathrm{~g} \mathrm{~mol}^{-1}\right)\end{array}$ & $\begin{array}{l}\mathrm{M}_{w} \times 10^{3} \\
\left(\mathrm{gmol}^{-1}\right)\end{array}$ & PDI \\
\hline \multirow[t]{3}{*}{$70 / 30$} & 12 & 100 & $\mathrm{Sn}(\mathrm{Oct})_{2}$ & Crosslinked & - & - & - \\
\hline & & 90 & & $91.5 / 8.5$ & 1.96 & 2.99 & 1.5 \\
\hline & & 80 & & $91.4 / 8.6$ & 1.66 & 2.42 & 1.5 \\
\hline \multirow[t]{2}{*}{$80 / 20$} & 10 & 100 & $\mathrm{Sn}(\mathrm{Oct})_{2}$ & Crosslinked & - & - & - \\
\hline & 4 & & & $92.7 / 7.3$ & 4.82 & 11.01 & 2.3 \\
\hline \multirow[t]{2}{*}{$70 / 30$} & 10 & 100 & $\mathrm{Sn}(\mathrm{Oct})_{2}$ & Crosslinked & - & - & - \\
\hline & 4 & & & $86.4 / 13.4$ & 2.85 & 9.13 & 3.2 \\
\hline
\end{tabular}

Abbreviations: GMA, glycidyl methacrylate; LLA, lactic acid; NMR, nuclear magnetic resonance; P(LLA-co-GMA), poly(lactic acid-co-glycidyl methacrylate); PDI, polydispersity index. 


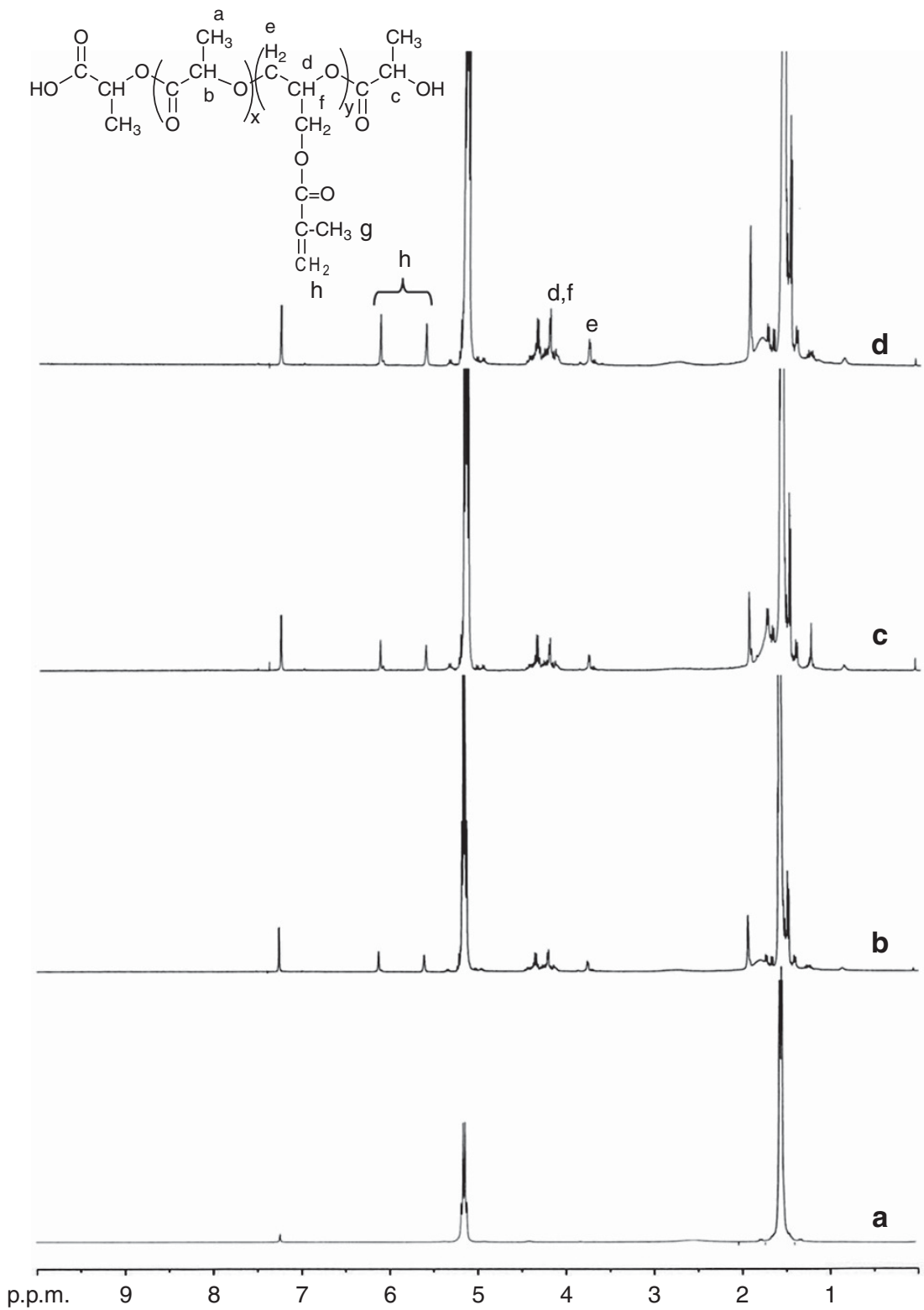

Figure $2{ }^{1} \mathrm{H}$ NMR spectra of P(LLA-co-GMA) copolymers at various GMA contents (a) 0 mol\% GMA, (b) $1.7 \mathrm{~mol} \%$ GMA, (c) $2.3 \mathrm{~mol} \%$ GMA and (d) $9.5 \mathrm{~mol} \% \mathrm{GMA}$.

Table 3 Effects of comonomer feed ratios on properties of P(LLA-co-GMA)

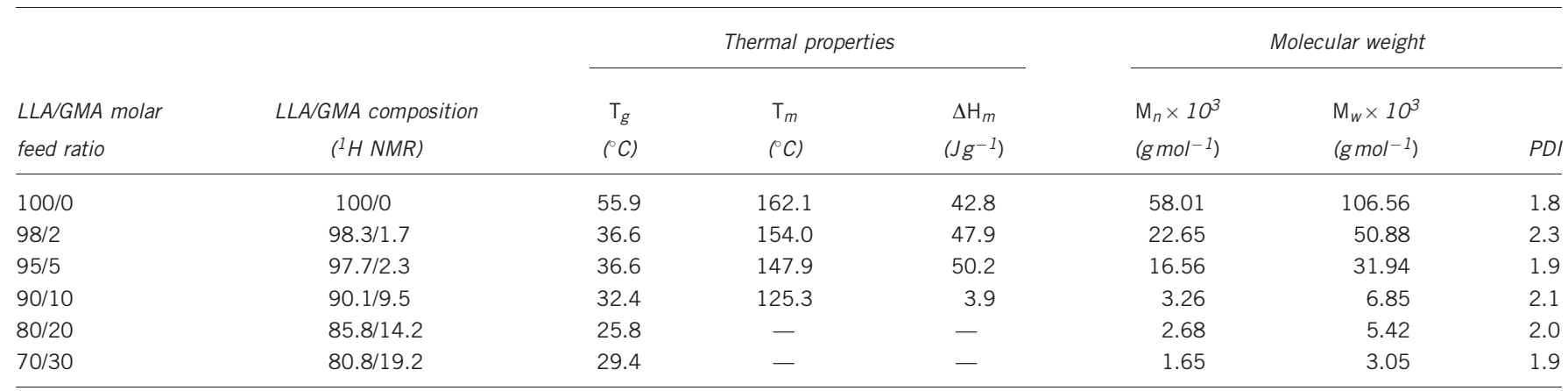

Abbreviations: GMA, glycidyl methacrylate; LLA, lactic acid; NMR, nuclear magnetic resonance; P(LLA-co-GMA), poly(lactic acid-co-glycidyl methacrylate); PDI, polydispersity index. All copolymers were prepared in solution process (THF) at $100^{\circ} \mathrm{C}$ for $24 \mathrm{~h}$. 
GMA feed compositions. This reflects that the introduction of GMA retarded the polymerization of LLA.

FTIR spectra, in the $1850-1550 \mathrm{~cm}^{-1}$ region, of P(LLA-co-GMA) copolymers are shown in Figure 3. Characteristic bands at 1760 and $1720 \mathrm{~cm}^{-1}$ are due to $\mathrm{C}=\mathrm{O}$ stretching modes of PLLA and GMA, whereas that at $1640 \mathrm{~cm}^{-1}$ was assigned to the $\mathrm{C}=\mathrm{C}$ stretching mode of GMA. A unique band at $815 \mathrm{~cm}^{-1}$ is due to a $-\mathrm{CH}_{2}$ deformation mode of GMA. The band ratio of the two $\mathrm{C}=\mathrm{O}$ stretching modes can be employed to determine the GMA content in the copolymer chains. Also, the 1640 and $815 \mathrm{~cm}^{-1}$ bands are conveniently used in quantitative measurements of the $\mathrm{C}=\mathrm{C}$ content, that is, the copolymer's GMA content, as the band was clearly separated from other vibrational modes. Results on band area of these modes were strongly correlated with the GMA contents calculated from ${ }^{1} \mathrm{H}$ NMR spectra.

DSC thermograms of P(LLA-co-GMA) copolymers are shown in Figure 4, and the correlation of copolymer's chain structures and thermal properties are summarized in Table 3. Melting temperature

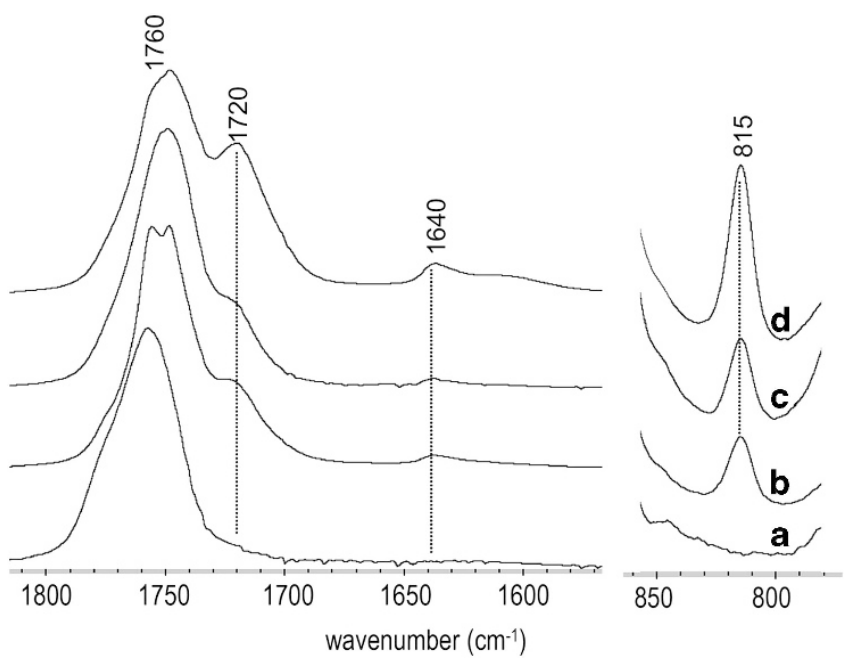

Figure 3 FTIR spectra of P(LLA-co-GMA) copolymers at various GMA compositions: (a) 0, (b) 9.5, (c) 14.2, and (d) 19.2 mol\% GMA.

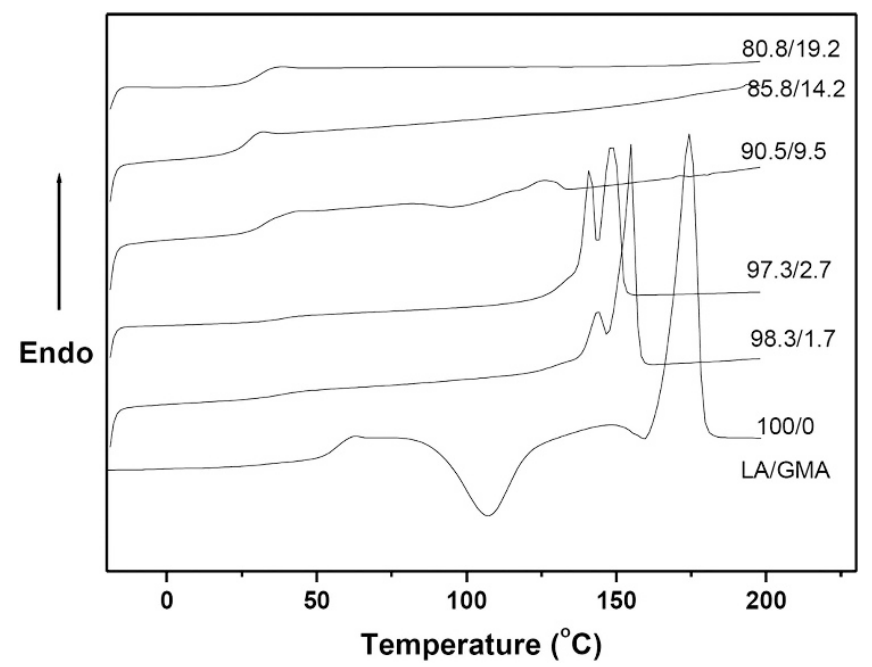

Figure 4 DSC thermograms of $\mathrm{P}(\mathrm{LLA}-\mathrm{CO}-\mathrm{GMA})$ copolymers with various GMA contents.
$\left(T_{\mathrm{m}}\right)$ of copolymers varied with the GMA content in the chains from $154-125^{\circ} \mathrm{C}$. The melting peak, associated with PLLA domains, shifted to lower temperature with an increase of GMA content, and disappeared when the content was higher than $14 \%$. This indicates the disruption of crystal formation of PLLA segments upon introduction of GMA units. Glass transition temperature $\left(T_{\mathrm{g}}\right)$ of the copolymers varied from $29-37^{\circ} \mathrm{C}$, compared with $56{ }^{\circ} \mathrm{C}$ for pure PLLA. The decrease of $T_{\mathrm{g}}$ with an increase in the GMA content was likely because the presence of side chains from comonomer units facilitated the segmental movements. The low molecular weight nature of the copolymers may also lead to a reduction in their $T_{\mathrm{g}}$ values. However, upon further increasing the GMA content $>19 \mathrm{~mol} \%$, the $T_{\mathrm{g}}$ of the copolymer started to increase, probably because of a domination of GMA characteristics, which has a high $T_{\mathrm{g}}$.

\section{Crosslinking behaviors of P(LLA-co-GMA)}

Curing behaviors of P(LLA-co-GMA) with various GMA content were investigated by photo- and thermo-crosslinking processes. The detailed results are as follows:

Photo-crosslinking process. Effects of irradiation time and the initiator content on crosslinking efficiency were examined via the measurement of gel content. The initiator and the copolymer's GMA contents were first fixed at $0.5 \mathrm{wt} \%$ and $9.5 \mathrm{~mol} \%$, whereas various crosslinking times at $2,4,6$, and $8 \mathrm{~min}$ were employed. Table 4 indicates that the gel content of all cured products derived from various times was significantly similar $(72-75 \%)$. The shortest curing time of 2 min was, therefore, chosen for further study to avoid deterioration of samples due to over-irradiation. When the initiator content was increased from 0.5 to $1.0 \mathrm{wt} \%$, the gel content increased from 72 to $86 \%$. A further increase in the content to 1.5 and $2 \mathrm{wt} \%$, however, led to no significant difference in the gel content. Therefore, a 1.0 -wt $\%$ initiator content was employed as a proper parameter, where the gel content of $86 \%$ was obtained. Given these results, it is apparent that the crosslink density of the cured products cannot be further increased by changing the irradiation conditions, unless the copolymer's GMA content is increased. Curing of the copolymers consisting of higher GMA compositions was then investigated by employing the pre-determined curing conditions. The gel content increased to 89 and $95 \%$, when copolymers constituting of 14.2 and $19.2 \mathrm{~mol} \%$ GMA were employed.

Table 4 Effects of GMA content, irradiated time and the initiator content on gel content (\%) of cured P(LLA-co-GMA) products

\begin{tabular}{lccc}
\hline $\begin{array}{l}\text { GMA content } \\
\text { (mol\%) }\end{array}$ & $\begin{array}{c}\text { Irradiated } \\
\text { time }(\text { min })\end{array}$ & $\begin{array}{c}\text { Initiator } \\
\text { content (\%) }\end{array}$ & $\begin{array}{c}\text { Gel content } \\
\text { (\%) }\end{array}$ \\
\hline 9.5 & 2 & 0.5 & $72.7 \pm 0.3$ \\
9.5 & 4 & 0.5 & $73.3 \pm 0.6$ \\
9.5 & 6 & 0.5 & $74.2 \pm 0.4$ \\
9.5 & 8 & 0.5 & $74.5 \pm 0.3$ \\
9.5 & 2 & 1.0 & $84.6 \pm 0.5$ \\
9.5 & 2 & 1.5 & $85.2 \pm 0.7$ \\
9.5 & 2 & 2.0 & $85.7 \pm 0.4$ \\
14.2 & 2 & 1.0 & $89.3 \pm 0.3$ \\
19.2 & 2 & 1.0 & $95.2 \pm 0.4$ \\
\hline
\end{tabular}

Abbreviations: GMA, glycidyl methacrylate; P(LLA-co-GMA), poly(lactic acid-co-glycidyl methacrylate). 
Thermo-crosslinking process. Effects of curing conditions on the gel content of crosslinked products derived from P(LLA-co-GMA) copolymer with $9.5 \mathrm{~mol} \%$ GMA were investigated by varying curing temperatures from $80-120^{\circ} \mathrm{C}$ and crosslinking times from $15 \mathrm{~min}$ to $6 \mathrm{~h}$. Figure 5 shows that the gel content values were strongly dependent on both parameters. The results indicate that the optimum conditions for thermo-crosslinking of this copolymer were $120^{\circ} \mathrm{C}$ and $15 \mathrm{~min}$, as this provided the highest gel content value at the shortest curing time. The use of higher temperature led to higher gel contents in shorter curing time. This is likely to be because at higher temperatures, unsaturated chain-pendants of the copolymer units had a high degree of movement that increased the efficiency of the crosslinking reaction. Chains translation may also have a role on the kinetics of this curing reaction. Given that these are related to the viscoelasticity of the copolymer, the time-temperature equivalence principle $^{22}$ is applicable to this curing behavior. Our attempt to preliminarily apply the principle to the data obtained from the curing reactions at different temperatures is shown in Figure 6, where master curves correlating the gel content and the curing time were constructed at three different temperatures by shifting of the curing time scale. The predicted values are beneficial in extrapolating the curing behaviors beyond the practical temperature range, either at

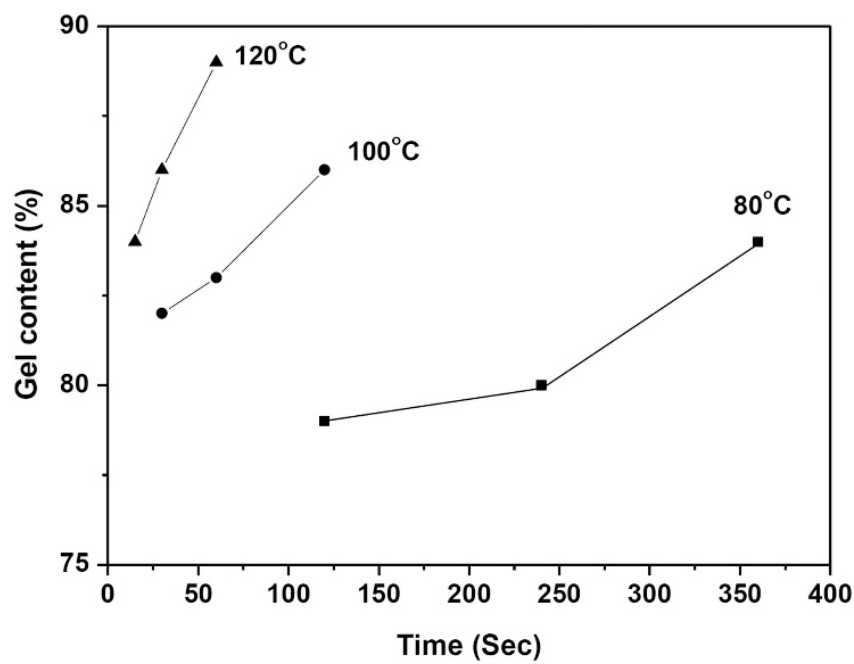

Figure $5 \mathrm{Gel}$ content (\%) of crosslinked P(LLA-co-GMA) as a function of crosslinking temperature and time. low temperatures, which require long curing time, or at high temperatures where thermal degradation may compete with the curing reaction.

\section{Mechanical properties}

Compressive stress and degree of swelling of the thermally cured products with various gel contents were measured. The results, as summarized in Table 5, indicate that compressive stress of copolymer samples increased with the gel (and GMA) contents. Up on introducing GMA units to PLLA chains, a drastic drop in the compressive stresses is observed (from $19.4 \mathrm{MPa}$ for neat uncured PLLA to 3.0 MPa for the copolymer containing $9.5 \mathrm{~mol} \% \mathrm{GMA})$. This is due to the much lower MW and crystalline content $\left(\Delta H_{\mathrm{m}}\right)$ of the copolymer sample (Table 3). An increasing trend of the compressive stress as a function of GMA content, that is, the crosslink density, is observed in P(LLA-co-GMA) cured samples, despite a decrease in their original MW and crystalinity (Table 3). This indicates a dominating effect of the crosslink density on the compression stress, which represents viscoelastic behavior of the cured samples. It was observed that $T_{\mathrm{g}}$ of the cured products increased by $15-20^{\circ} \mathrm{C}$, compared with that of the original copolymer samples, as shown in Figure 7, indicating movement restriction of polymer segments, especially chain-ends, due to the formation of crosslink points. It is concluded that the thermal and mechanical properties of the copolymers can be enhanced by the crosslinking process. As expected, the degree of swelling of the cured samples decreased with an increase in the crosslink density (gel content).

Table 5 Compressive stress and degree of swelling of cured P(LLA-co-GMA) products

\begin{tabular}{lccr}
\hline $\begin{array}{l}\text { GMA content } \\
(\mathrm{mol} \%)\end{array}$ & $\begin{array}{c}\text { Gel content } \\
(\%)\end{array}$ & $\begin{array}{c}\text { Degree of swelling } \\
(\%)\end{array}$ & $\begin{array}{r}\text { Compressive } \\
\text { stress (MPa) }\end{array}$ \\
\hline O $^{\mathrm{a}}$ & - & - & $19.4 \pm 3.1$ \\
9.5 & $84.6 \pm 1.2$ & $451.6 \pm 0.6$ & $3.0 \pm 0.1$ \\
14.2 & $88.6 \pm 0.9$ & $352.2 \pm 0.3$ & $5.9 \pm 0.4$ \\
19.2 & $95.2 \pm 0.4$ & $54.4 \pm 0.4$ & $25.5 \pm 0.1$
\end{tabular}

Abbreviations: GMA, glycidyl methacrylate; P(LLA-co-GMA), poly(lactic acid-co-glycidyl methacrylate).

aUncured PLLA sample.
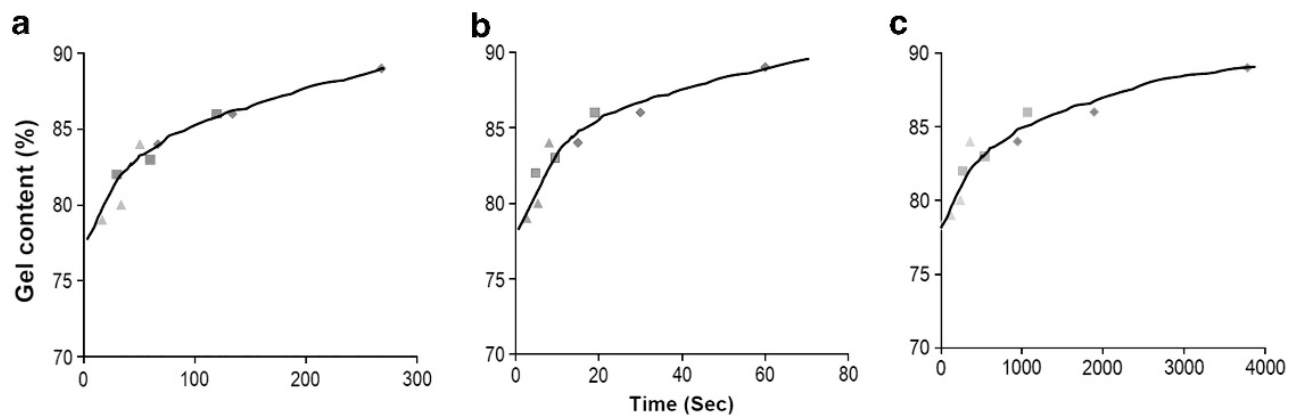

Figure 6 Predicted gel content of crosslinked P(LLA-co-GMA) as a function of curing time at: (a) 120, (b) 100, and (c) $80^{\circ} \mathrm{C}$, calculated from the timetemperature equivalence principle. 


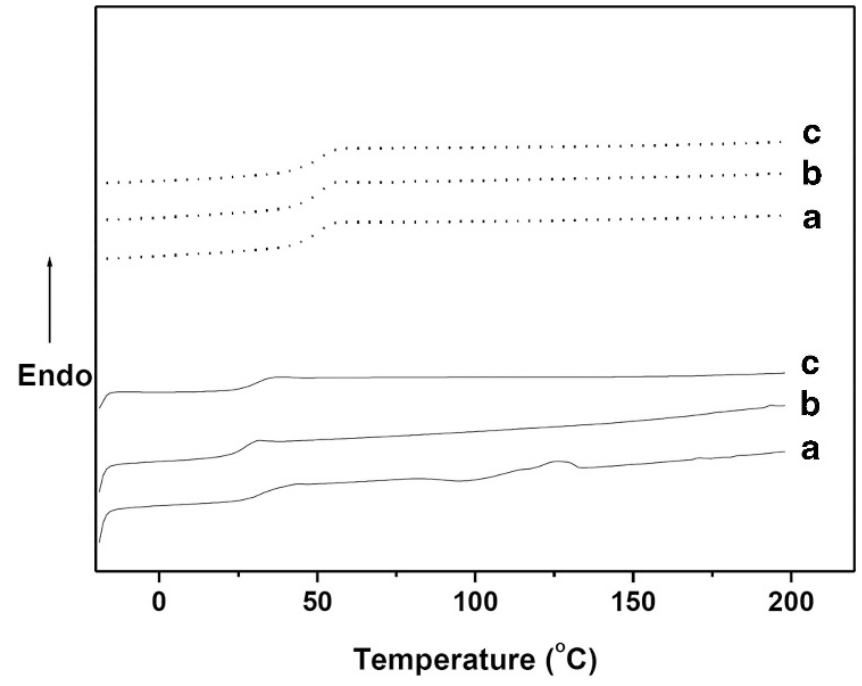

Figure 7 DSC thermograms of cured (dash line) and original (solid line) copolymers. consisting of various GMA compositions: (a) $9.5 \mathrm{~mol} \%$, (b) 14.2 and (c) $19.2 \mathrm{~mol} \%$.

\section{CONCLUSION}

Curable P(LLA-co-GMA) copolymers, which possess biocompatible and degradable properties, were synthesized via ring-opening polymerization. Effect of catalyst types and their content on efficiency of the reaction was examined, with tin octoate observed as the most effective catalyst. GMA composition and chain structures of the copolymers are controllable by adjusting the GMA monomer feed composition and reaction conditions. Thermal properties and curing behaviors of the resulting copolymers are strongly dependent on GMA content in the copolymer chains, and also curing processes and conditions. The photo-crosslinking process is proven as a practical method in the curing of the copolymers, because the reaction is almost complete within $2 \mathrm{~min}$, as indicated by gel content results. Mechanical and thermal properties of the cured products are enhanced, with the degree of improvement being dependent on the content of the curable GMA units. The resulting copolymers have high potential for use in biomedical applications, where biocompatibility, degradability and high strength are required.

\section{ACKNOWLEDGEMENTS}

This research was supported by a grant of the National Metal and Materials Technology Center through the funding no. MT-B-52-ENV-07-032-I.
1 Moon, S., Lee, C., Taniguchi, I., Miyamoto, M. \& Kimura, Y. Melt/solid polycondensation of L-lactic acid: an alternative route to poly(L-lactic acid) with high molecular weight. Polymer 42, 5059-5062 (2001).

2 Zhang, J., Lou, J., Ilias, S., Krisnamachari, P. \& Yan, J. Thermal properties of poly(lactic acid) fumed silica nanocomposites: Experiments and molecular dynamics simulations. Polymer 49, 2381-2386 (2008).

$3 \mathrm{Wu}$, L., Cao, D., Huang, Y. \& Li, B.-G. Poly(L-lactic acid)/SiO 2 nanocomposites via in situ melt polycondensation of L-lactic acid in the presence of acidic silica sol: preparation and characterization. Polymer 49, 742-748 (2008)

4 Yan, S., Yin, J., Yang, Y., Dai, Z., Ma, J. \& Chen, X. Surface-grafted silica linked with L-lactic acid oligomer: a novel nanofiller to improve the performance of biodegradable poly(L-lactide). Polymer 48, 1688-1694 (2007).

5 Wang, N., Zhang, X., Ma, X. \& Fang, J. Influence of carbon black on the properties of plasticized poly(lactic acid) Composites. Polym. Degrad. Stabil. 93, 1044-1052 (2008).

6 Ouchi, T., Ichimurs, S. \& Ohya, Y. Synthesis of branched poly(lactide) using polyglycidol and thermal mechanical properties of its solution-cast film. Polymer 47, 429-434 (2006).

7 Chen, Y. Z., Yan, W. H. \& Ping, Q. Y. Morphology and properties of hybrid composites based on polypropylene/polylactic acid blend and bamboo fiber. Bioresource Technol. 101, 7944-7950 (2010)

8 Bitinis, N., Verdejo, R., Maya, E. M., Espuche, E., Cassagnau, P. \& Lopez-Manchado, M. A. Physicochemical properties of organoclay filled polylactic acid/natural rubber blend bionanocomposites. Compos. Sci. Technol. 72, 305-313 (2012).

9 Guan, J., Eskridge, M. K. \& Hanna, A. M. Acetylated starch-polylactic acid loose-fill packaging materials. Ind. Crop. Prod. 22, 109-123 (2005).

10 Liu, M., Yin, Y., Fan, Z., Zheng, X., Shen, S., Deng, P., Zheng, C., Teng, H. \& Zhang, W. The effects of gamma-irradiation on the structure, thermal resistance and mechanical properties of the PLA/EVOH blends. Nucl. Instrum. Methods B274, 139-144 (2012).

11 Lu, D., Yang, L., Zhou, T. \& Lei, Z. Synthesis, characterization and properties of biodegradable polylactic acid-b-cyclodextrin cross-linked copolymer microgels. Eur. Polym. J. 44, 2140-2145 (2008).

12 Kimura, Y. Molecular, structure, and material design of bio-based polymers. Polym. J. 41, 797-807 (2009).

13 Tsuji, H. \& Ikada, Y. Stereocomplex formation between enantiomeric poly(lactic acid)s. XI. - Mechanical properties and morphology of solution-cast films. Polymer 40, 6699-6708 (1999).

14 Louis, M. P., Hait, B. S., Lanyk, J. T. \& Knauss, M. D. Linear and branched architectures from the polymerization of lactide with glycidol. Macromolecules 40, 2327-2334 (2007)

15 Petchsuk, A., Nakayama, A. \& Aiba, S. Synthesis and biodegradability of L-lactide/ glycidol copolymers. Polym. Degrad. Stabil. 94, 1700-1706 (2009).

16 Kumar, M., Mohanty, S., Nayak, S. K. \& Parvaiz, M. R. Effect of glycidyl methacrylate (GMA) on the thermal, mechanical and morphological property of biodegradable PLA/PBAT blend and its nanocomposites. Bioresource Technol. 101, 8406-8415 (2010)

17 Su, Z., Li, Q., Liu, Y., Hu, G. -H. \& Wu, C. Compatibility and phase structure of binary blends of poly(lactic acid) and glycidyl methacrylate grafted poly(ethylene octane). Eur. Polym. J. 45, 2428-2433 (2009).

18 Zhang, N., Wang, Q. \& Ren, J. Preparation and properties of biodegradable poly(lactic acid)/poly(butylne adipate-co-terephthalate) blend with glycidyl methacrylate as reactive processing agent. J. Mater. Sci. 44, 250-256 (2000).

19 Helminen, A. O., Korhonen, H. \& Seppala, J. V. Structure modification and crosslinking of methacrylated polylactide oligomer. J. Appl. Polym. Sci. 86, 3616-3624 (2002).

20 Helminen, A. O., Korhonen, H. \& Seppala, J. V. Crosslinked poly(ester anhydride)s based on poly(E-caprolactone) and polylactide oligomers. J. Polym. Sci. Pol. Chem. 41 3788-3797 (2003)

21 McCabe, J. F. Applied dental materials (Blackwell scientific publications, London, 1990)

22 Macosko, C. W. Rheology Principles Measurements and Applications (VCH Publishers Inc., USA, 1994). 